\title{
Dynamics of putative sex pheromone components during heat periods in estrus-induced cows
}

\author{
R. Mozūraitis, ${ }^{*} \dagger^{1}$ J. Kutra, $\ddagger$ A.-K. Borg-Karlson, $\dagger$ and V. Būda* \\ *Laboratory of Chemical and Behavioural Ecology, Institute of Ecology, Nature Research Centre, LT-08412 Vilnius, Lithuania \\ †Ecological Chemistry Group, Division of Organic Chemistry, Department of Chemistry, School of Chemistry and Engineering, \\ Royal Institute of Technology, SE-10044 Stockholm, Sweden \\ †Institute of Animal Science, Lithuanian University of Health Sciences, LT-82317 Baisogala, Lithuania
}

\begin{abstract}
Determination of the optimal insemination time in dairy cows is vital for fertilization success and is a challenging task due to silent or weak signs of estrus shown by some cows. This can be overcome by combining several estrus detection methods, leading to higher detection rates. However, an efficient, noninvasive method for detecting estrus in cows is still needed. Chemical cues released by the cow during estrus have been proposed to have pheromonal properties and signal readiness to mate to the bull. Such cues could be used in an industrial setting to detect cows in estrus. However, no conclusive published data show temporal changes in putative sex pheromone levels during estrus. The goal of this study was to determine the temporal pattern of putative sex pheromone components during estrus and to assess the reproducibility of changes in pheromone concentration with respect to ovulation time. Two injections of the hormone $\mathrm{PGF}_{2 \alpha}$ were administered over a 2 -wk interval to induce and synchronize the estrous cycles of 6 Holstein cows. The precise time of ovulation was determined by means of an ultrasound technique, and estrus was determined by visual observation. Using solid-phase microextraction gas chromatography-mass spectrometry techniques, we showed that acetic and propionic acids, which have been proposed to be putative sex pheromone components in cows, were present in the headspaces of all estrous and diestrous fecal samples, whereas 1-iodoundecane was not detected by solid-phase microextraction or by solvent extraction with diethyl ether. Low levels of acids were observed until $1 \mathrm{~d}$ before ovulation, at which point their concentrations increased, peaking around $0.5 \mathrm{~d}$ before ovulation. The application of labeled synthetic standards revealed that during the peak of release, 36 $\pm 8 \mathrm{ng}$ (average $\pm \mathrm{SD}$ ) of acetic acid and $10 \pm 3 \mathrm{ng}$ of
\end{abstract}

Received November 30, 2016.

Accepted May 5, 2017.

${ }^{1}$ Corresponding author: raimondas.mozuraitis@su.se propionic acid were present in 0.5-g samples of estrousphase fecal matter compared with $19 \pm 5$ and $2.3 \pm$ $1 \mathrm{ng}$ of acetic and propionic acids, respectively, in the control diestrous samples. After the peak, the amounts of the compounds decreased sharply to match those of the control samples and afterward returned to the baseline readings. This decrease in the amounts of putative pheromone components was registered about 12 $\mathrm{h}$ before ovulation, indicating that acetic and propionic acids could be used as biomarkers for the electronic detection of ovulation.

Key words: dairy cow, estrus, ovulation, headspace, putative pheromone

\section{INTRODUCTION}

Milk production and reproductive performance are 2 major components of dairy cow profitability (LeBlanc, 2010). Decreasing fertility has been a growing concern to dairy farmers over the past few decades (Nordéus et al., 2016). It has been shown that a $1 \%$ change in pregnancy rate is valued at between $\$ 22$ and $\$ 35 /$ cow per year (Lima et al., 2010). Among other factors, the pregnancy rate depends on fertilization success; this constraint is influenced by optimal insemination time, which is determined by the effective detection of estrus (Roelofs et al., 2010). Many studies have compared pregnancy rates for various intervals between the detection of estrus and AI. With a twice per day heat check, insemination is recommended to be carried out 12 to $18 \mathrm{~h}$ after the detection of estrus. If the commencement of estrus is detected more precisely using an electronic heat detection system, AI should proceed within 4 to $12 \mathrm{~h}$ of the observation of estrus (reviewed in Roelofs et al., 2010).

Considerable variation in the time interval between estrus and ovulation indicates that pregnancy rates may be higher when the timing of AI is determined with respect to ovulation rather than the onset of standing estrus (Hernández-Cerón et al., 1993; Saumande and Humblot, 2005; Bloch et al., 2006). Only a few stud- 
ies have been conducted that take into consideration the time of ovulation when investigating the optimal insemination time for dairy cows. Some studies have demonstrated that pregnancy rates increased as the insemination time approached the time of ovulation and started to decline when insemination occurred after ovulation (Pursley et al., 1998; Van Eerdenburg et al., 2002; Hockey et al., 2010), whereas other studies have revealed that pregnancy rates peaked following insemination 6 to $12 \mathrm{~h}$ before ovulation and then declined (Dalton et al., 2001; Roelofs et al., 2006; Saacke, 2008; Stevenson et al., 2014).

It is difficult to predict the exact time of ovulation except by palpating the ovary through the rectal wall, applying an ultrasonic technique, or measuring concentrations of certain hormones in the blood. All these invasive techniques disturb the cow, increase the risk of injury and infection, require a qualified examiner, are time consuming, and have to be applied often to determine the exact time of ovulation. Vaginal electrical resistance may be used to predict ovulation time (Schams et al., 1977; Saumande, 2002). It was shown that the lowest vaginal electrical resistance values generally occurred close to the time of ovulation (Schams et al., 1977). This method is still under development, and it has some drawbacks. For example, Hockey et al. (2010) reported that on several occasions the values could not be determined due to unstable readings, which occurred when air was trapped in the vaginal cavity.

Artificial olfaction systems, such as electronic nose technology, are increasingly used for the rapid detection of odor fingerprints of biological processes (Sankaran et al., 2012; Burlachenko et al., 2016). The use of an electronic nose for the routine determination of optimal insemination time in cows requires the easy obtainable matrix - the reliable excretion of volatile chemical markers - where the absolute concentrations show clear, reproducible, temporal patterning and provide information about the timing of ovulation. Estrus-specific compounds have been identified in feces, urine, milk, vaginal fluids, saliva, and serum, and some of those compounds showed pheromone activities (Vytas et al., 2012; Archunan et al., 2014; Le Danvic et al., 2015; Nordéus et al., 2016). Feces are easy to collect and quantify, and, as studies indicate that volatile sex pheromones are used to signal readiness for mating and may be a reliable chemical marker, could potentially be used for estrus detection by an electronic nose. Sankar and Archunan (2008) reported that acetic and propionic acids, as well as 1-iodoundecane, were excreted in cow feces and were shown to be unique in the estrous phase when the cow is receptive to the bull. The mixture of these 3 compounds, when applied to the genital region of diestrous cows, stimulated significantly increased flehmen and mounting behaviors in bulls compared with the control group treated with phenol. Hence, these 3 compounds were identified as bovine putative sex pheromone components and could be used as ovulation indicators in cows. However, no data showing the temporal patterning of the bovine putative sex pheromone during the estrous period have been published.

This study assessed the applicability of putative sex pheromone components as ovulation time indicators for use with electronic nose detection methods in Holstein cows with synchronized estrous cycles. The study objectives were (1) to describe the quantitative and qualitative composition of putative sex pheromones in cow feces using the solid-phase microextraction (SPME) method, (2) to determine the fine temporal patterning of putative sex pheromone components during estrus, and (3) to assess the temporal accuracy of changes in pheromone concentrations with respect to ovulation time.

\section{MATERIALS AND METHODS}

\section{Animals and Collection of Samples}

Six Holstein cows $(\mathrm{BW}=600-650 \mathrm{~kg}$; second or third lactation) from a dairy farm in Bernatoniu ZUB, Kaunas district, central Lithuania, were chosen for sample collection. The cows were fed twice a day on a Keenan mixing delivery system (Keenan System Better Farming Food Technology, Carlow, Ireland). The daily rations for each cow were $12.0 \mathrm{~kg}$ of haylage, $14.0 \mathrm{~kg}$ of corn silage (maize grain silage, $60 \% \mathrm{DM}$ ), $3.0 \mathrm{~kg}$ of hay, $1.0 \mathrm{~kg}$ of molasses sugar beet, $8.0 \mathrm{~kg}$ of concentrates (comprising 20\% rapeseed cake, $18 \%$ soybean meal bearing $46 \%$ protein, $10 \%$ field beans, and $52 \%$ oats), $0.5 \mathrm{~kg}$ of protected fat, and $0.2 \mathrm{~kg}$ of mineral and vitamin mix. Two injections of $5 \mathrm{~mL}$ of the hormone $\mathrm{PGF}_{2 \alpha}(5 \mathrm{mg} /$ $\mathrm{mL}$ of the active substance dinoprost; Dinolytic, Pfizer Manufacturing Belgium Nv/SA, Puurs, Belgium) were given at a 2-wk interval to induce and synchronize the estrous cycles in the cows. The ovulation was observed approximately $3 \mathrm{~d}$ after the last hormone treatment. The precise time of ovulation was determined by means of an ultrasound technique using a $47-63 \mathrm{~Hz}$ 100LC scanner (Pie Medical, Maastricht, the Netherlands). The scanning was performed twice per day at $\mathrm{d} 2$ and 1 before ovulation and 4 times per day (i.e., at 8, 16, 20, and $24 \mathrm{~h}$ ) at the day of ovulation. In addition, the most suitable time for insemination was determined based on behavioral observations by monitoring the presence or absence of a standing reflex, movement intensity, and snuggling at 4-h intervals. Just before insemination, the 
Table 1. Compounds collected from the headspace of fecal samples during the diestrous control (sample $-6 \_8$; day and hour of the sample collection with respect to ovulation time) and during the peak of release in estrus

\begin{tabular}{|c|c|c|c|c|}
\hline No. & Compound name & Control & Estrous & $P$-value \\
\hline 1 & Toluene & $16.78 \pm 5.45$ & $18.39 \pm 4.59$ & NS \\
\hline 2 & U1 & $0.75 \pm 0.49$ & $0.64 \pm 0.37$ & NS \\
\hline 3 & Butanol & $1.34 \pm 0.34$ & $3.08 \pm 1.11$ & NS \\
\hline 4 & Pentanol & $1.64 \pm 0.90$ & $4.43 \pm 1.83$ & NS \\
\hline 5 & 2-Octanone & $0.12 \pm 0.03$ & $0.33 \pm 0.14$ & NS \\
\hline 6 & 6-Methyl-5-hepten-2-one & $0.70 \pm 0.40$ & $1.27 \pm 0.36$ & 0.049 \\
\hline 7 & Hexanol & $0.71 \pm 0.51$ & $1.11 \pm 0.45$ & NS \\
\hline 8 & 2-Nonanone & $0.18 \pm 0.13$ & $0.39 \pm 0.26$ & NS \\
\hline 9 & U2 & $12.50 \pm 8.32$ & $17.22 \pm 11.59$ & NS \\
\hline 10 & Acetic acid & $21.13 \pm 5.32$ & $92.22 \pm 44.48$ & 0.028 \\
\hline 11 & U3 & $0.29 \pm 0.16$ & $0.31 \pm 0.18$ & NS \\
\hline 12 & Benzaldehyde & $1.26 \pm 0.62$ & $0.66 \pm 0.16$ & NS \\
\hline 13 & Propanoic acid & $12.79 \pm 7.92$ & $38.66 \pm 18.87$ & 0.028 \\
\hline 14 & 2-Methylpropanoic acid & $0.76 \pm 0.33$ & $0.93 \pm 0.65$ & NS \\
\hline 15 & Hexadecane & $0.88 \pm 0.56$ & $0.83 \pm 0.31$ & NS \\
\hline 16 & Butanoic acid & $22.96 \pm 9.95$ & $125.83 \pm 57.55$ & 0.028 \\
\hline 17 & 3-Methylbutanoic acid & $1.28 \pm 0.49$ & $6.12 \pm 2.35$ & 0.028 \\
\hline 18 & $\alpha$-Ionone & $0.31 \pm 0.15$ & $0.21 \pm 0.04$ & NS \\
\hline 19 & Dodecanal & $0.44 \pm 0.23$ & $0.90 \pm 0.27$ & NS \\
\hline 20 & Pentanoic acid & $7.17 \pm 4.82$ & $44.11 \pm 22.86$ & 0.046 \\
\hline 21 & U4 & $0.37 \pm 0.21$ & $0.28 \pm 0.07$ & NS \\
\hline 22 & 4-Methylpentanoic acid & $0.99 \pm 0.55$ & $1.64 \pm 0.78$ & NS \\
\hline 23 & U5 & $1.10 \pm 0.59$ & $0.93 \pm 0.47$ & NS \\
\hline 24 & U6 & $0.31 \pm 0.11$ & $0.68 \pm 0.39$ & NS \\
\hline 25 & a-Ethylcaproic acid & $0.11 \pm 0.03$ & $0.19 \pm 0.08$ & NS \\
\hline 26 & $p$-Cresol & $4.40 \pm 2.84$ & $4.26 \pm 1.29$ & NS \\
\hline 27 & $o-, m-$, or $p$-Ethylphenol & $0.23 \pm 0.18$ & $0.37 \pm 0.14$ & NS \\
\hline 28 & Indole & $0.43 \pm 0.15$ & $3.51 \pm 2.33$ & 0.028 \\
\hline 29 & U7 phthalate type & $0.38 \pm 0.31$ & $0.16 \pm 0.10$ & NS \\
\hline 30 & Hexadecanoic acid & $3.72 \pm 1.39$ & $2.29 \pm 0.79$ & NS \\
\hline 31 & Octadecanoic acid & $3.80 \pm 1.67$ & $1.91 \pm 0.83$ & NS \\
\hline
\end{tabular}

${ }^{1}$ No. = number of compounds; $U=$ unidentified compound. The number in the control and estrous columns is the average intensity $(n=6)$ in millions, which correlates with the amount of the compound \pm SE. Values in bold differ significantly (Wilcoxon matched pairs test for dependent samples) between the diestrous control and during the peak of release in estrus.

tonus of the uterus was checked by rectal palpation and the condition of the cervix uteri was assessed. The collection of samples was started $2 \mathrm{~d}$ after the second hormone treatment and continued at 4-h intervals for $32 \mathrm{~h}$. Two sets of control diestrous samples from each cow were collected $3 \mathrm{~d}$ before and $10 \mathrm{~d}$ after the second hormone treatment. Feces were collected from the rectum, placed into $50-\mathrm{cm}^{3}$ vials, immediately frozen, and kept in a freezer at $-20^{\circ} \mathrm{C}$. In total, 11 samples from each cow were selected for analysis. These were placed on dry ice in a thermobox and transported to the laboratory.

\section{Chemicals}

Acetic acid isotope $\left(1,2-{ }^{13} \mathrm{C}, 99 \%\right)$ and deuterium labeled propionic acid (2,2-D, 98\%) samples (both from Cambridge Isotope Laboratories Inc., Andover, MA) were used for the quantification of the putative sex pheromone components. As standards for the determination of retention time and detection limits, 1-iodoundecane $(98 \%$ purity), acetic acid ( $>99 \%$ purity), and propionic acid ( $>99 \%$ purity; all from Sigma-Aldrich, St. Louis, MO) were used. Water (liquid chromatography/MS grade; Fisher Scientific, Waltham, MA) and diethyl ether (pro-analysis purity $>99.9 \%$; J. T. Baker Europe, Deventer, the Netherlands) were used as solvents. The remaining compounds mentioned in Table 1 were available from the GC standard collection stored at the ecological chemistry group at Royal Institute of Technology (Stockholm, Sweden).

\section{Analysis of Samples}

For each sample, $3 \mathrm{~g}$ of frozen feces was transferred into a glass vial. The sample was defrosted and mixed, and afterward $0.5 \mathrm{~g}$ of feces was transferred to a $1.5-\mathrm{mL}$ sampling vial, which was closed with a polytetrafluoroethylene-silicone septa and open-top screw cap (Supelco, Bellefonte, PA). The SPME method was used to collect the compounds released from the fecal samples. The SPME fibers coated with Carboxen/polydimethylsiloxane (Supelco) for trapping volatile compounds were selected based on data dealing with the choice 
of optimal SPME adsorbence type for VFA collection (Mills and Walker, 2000). An increase in temperature enhances the method sensitivity; however, some compounds may be sensitive to higher temperatures and will be either decomposed or oxidized by the air in the headspace vial (Kolb and Ettre, 2006). In light of this, each sample was preheated to approximately $36^{\circ} \mathrm{C}$, which is close to cow body temperature, in a heating block for $20 \mathrm{~min}$. Before each collection, the purification of SPME fibers was carried out at $270^{\circ} \mathrm{C}$ for $8 \mathrm{~min}$ in a GC injector, eliminating compound carryover in the SPME fibers. Afterward, the needle of an SPME syringe was used to pierce through the vial septum, and the fiber was exposed to the headspace and placed a few millimeters above the sample. Sorption was conducted at $36^{\circ} \mathrm{C}$ for $1 \mathrm{~h}$. During this period, equilibrium of short-chain acids between fiber and headspace was expected to be reached (Mills and Walker, 2000), and the GC analysis of the previous sample was completed. Fiber purity was checked daily. The analyses were performed using a GC/MS system (3400 gas chromatograph, Varian Inc., Palo Alto, CA; Finnigan SSQ 7000 mass spectrometer, Thermo Finnigan, San Jose, CA). An HP-FFAP capillary column $(30 \mathrm{~m} \times 0.25 \mathrm{~mm}$ i.d., $0.25 \mu \mathrm{m}$ film thickness; J\&W Scientific, Folsom, CA) devoted to fatty acid analyses (Agilent Technologies Inc., 2012) was used with a temperature program of $40^{\circ} \mathrm{C}$ for $2 \mathrm{~min}$, increasing by $4^{\circ} \mathrm{C} / \mathrm{min}$ to $132^{\circ} \mathrm{C}$, then increasing by $10^{\circ} \mathrm{C} / \mathrm{min}$ to $230^{\circ} \mathrm{C}$, and thereafter maintaining at $230^{\circ} \mathrm{C}$ for $15 \mathrm{~min}$. The split/splitless injector temperature was $230^{\circ} \mathrm{C}$, and the splitless period lasted for 2 min. Helium was used as the carrier gas with an inlet pressure of $70 \mathrm{kPa}$. Electron ionization mass spectra were determined at $70 \mathrm{eV}$ with the ion source at $150^{\circ} \mathrm{C}$.

The chromatographic data of volatiles collected from samples were compared by calculating the abundance of the ions formed from total ion chromatograms using X-calibur version 3.1 (Thermo Finnigan). Amounts of volatiles collected from an empty vial, which served as a control, were subtracted from those of fecal samples. The identities of volatile compounds were determined by comparing their chromatographic and mass spectra data with those presented in the National Institute of Standard and Technology electronic library (version 2.0) and with those of synthetic standards available at the ecological chemistry group, Royal Institute of Technology.

\section{Quantification of Acetic and Propionic Acids}

For quantification of acetic and propionic acids, calibration solutions of acetic acid isotope $\left(1,2-{ }^{13} \mathrm{C}\right)$ and deuterium labeled propionic acid $(2,2-\mathrm{D})$ at the concentrations 1,5 , and $25 \mu \mathrm{g} / \mathrm{mL}$ were prepared using LC/MS-grade water. Ten microliters of the solution was added to a sampling vial containing $0.5 \mathrm{~g}$ of feces collected from cow 1,061 six days before ovulation, and the matrix was mixed. Sampling and analysis were carried out following the protocol described above except the mass spectrometer was operated in selected ion monitoring (SIM) mode.

The molecular ions at a mass:charge ratio $(\mathrm{m} / \mathrm{z}) 60$ \pm 0.5 and $74 \pm 0.5$ were selected to monitor unlabeled acetic and propionic acids, respectively, whereas the molecular ions that were 2 Da heavier at $\mathrm{m} / z 62 \pm 0.5$ and $76 \pm 0.5$ were used to monitor the labeled analogs of the respective acids. A correlation between the known amounts of labeled fatty acids added to the 0.5g sample of feces, and the amounts of the compounds trapped on the SPME fiber that were expressed as areas under the chromatographic peaks were established. Afterward, amounts of the unlabeled acids present in each 0.5 -g fecal sample were calculated by measuring the areas under the chromatographic peaks and applying the established correlations between peak areas and amounts of labeled acids.

\section{Determination of Detection Limits for 1-lodoundecane}

For the determination of detection limits of the SPME/GC/MS method, solutions of 10, 50, 100, and $500 \mathrm{ng} / \mathrm{mL}$ of synthetic 1-iodoundecane in diethyl ether (pro-analysis purity) were prepared and $10 \mu \mathrm{L}$ of solution was added to a sampling vial containing $0.5 \mathrm{~g}$ of feces. After the matrix was mixed, sampling by SPME and subsequent analyses were carried out following the protocol described in the Analysis of Samples section except the mass spectrometer was operated in SIM mode, combining the selected ions at $m / z 43,57,71$, 85 , and 155 .

\section{Solvent Extraction of 1-lodoundecane}

To check whether 1-iodoundecane is detectable by solvent extraction, we followed the method used by Sankar and Archunan (2008). Three fecal samples were chosen for analyses [cow 6,682, sample 0_8 (day and hour of the sample collection in respect to ovulation time); cow 8,175, sample 0_8; and cow 8,256, sample $\left.0 \_12\right]$ when the highest amounts of acetic and propionic acids were detected. Fifteen milligrams of feces was transferred to a $25-\mathrm{mL}$ glass vial containing $15 \mathrm{~mL}$ of diethyl ether and a magnet for agitation. The vial was closed, and the extraction was allowed to proceed for 20 min at room temperature. Afterward, the supernatant was filtered through a column with $20 \mathrm{mg}$ of silica gel 


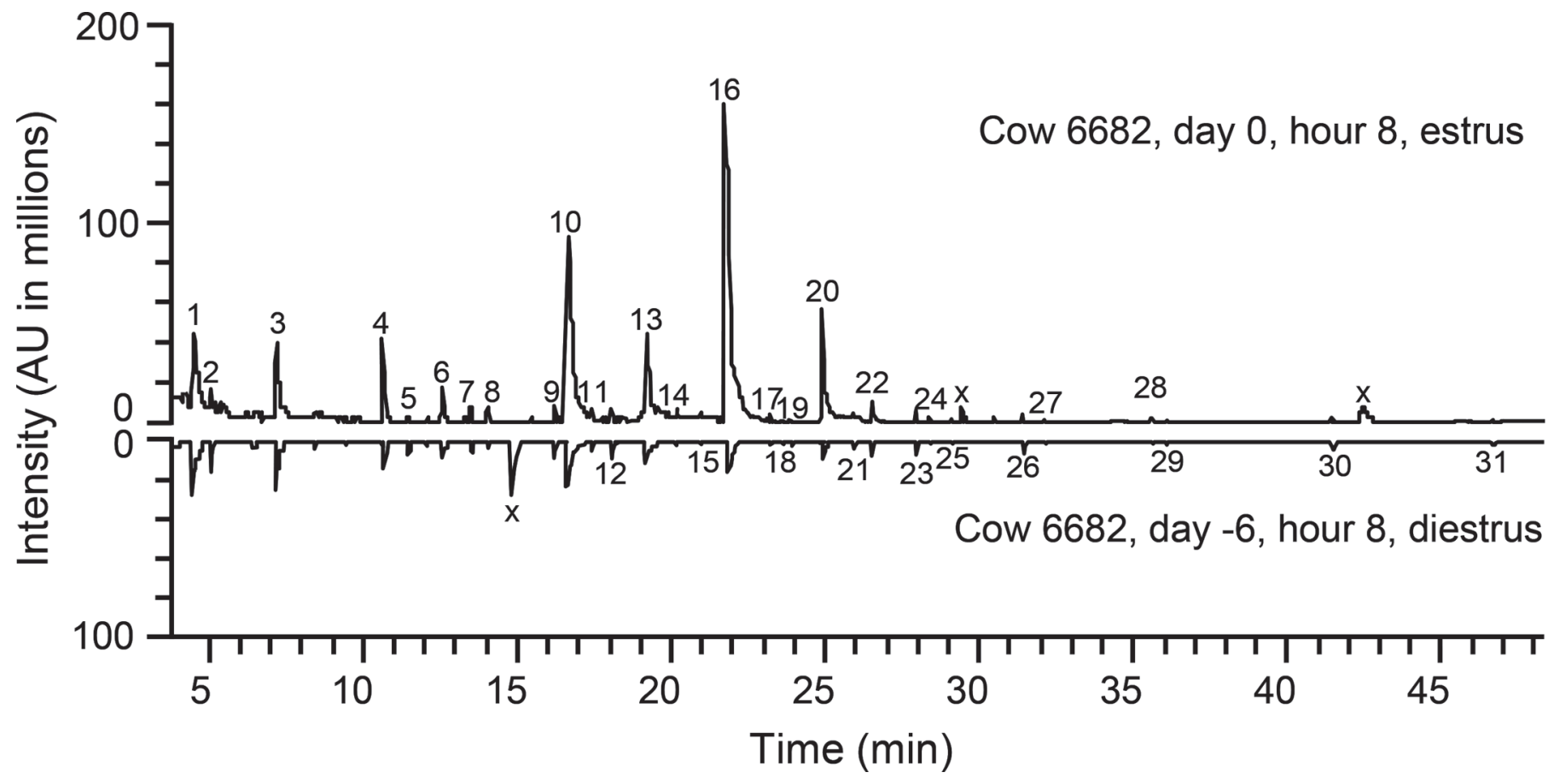

Figure 1. Representative chromatograms of volatiles collected from the headspace of fecal samples of a cow in estrus and diestrus. Fecal samples were collected from cow 6,682 in estrus d $0, \mathrm{~h} 8$ (i.e., at the day of ovulation) and in diestrus $\mathrm{d}-6$, h 8 (i.e., $6 \mathrm{~d}$ before ovulation). Intensity values presented on the $y$-axis indicate the abundance of the ions formed and correspond to the amounts of the compounds analyzed. Names of the compounds indicated by numbers are given in Table 1 . X indicates that the compound originated from a fiber and should be considered an artifact.

(60-120 mesh). The filtered extract was reduced to 1.5 $\mathrm{mL}$ by gentle nitrogen flow, and $1 \mu \mathrm{L}$ of it was injected into the GC/MS system operated in SIM mode and monitored for the selected ions at $m / z 43,57,71,85$, and 155 .

\section{Statistical Analysis}

Comparisons between the amounts of compounds present in the control samples (-6_08) and samples taken during the putative release peak were performed using a nonparametric Wilcoxon matched pairs test for dependent samples (Sokal and Rohlf, 1995) run by the computer program package Statistica (version 12; StatSoft Scandinavia AB, Uppsala, Sweden).

\section{RESULTS}

\section{Composition of Volatiles in Fecal Matter and the Amounts of Bovine Putative Sex Pheromone}

The comparison of chromatographic profiles from volatiles obtained from fecal estrous samples and control samples revealed 31 volatile compounds. These were detected in the estrous samples of all 6 cows and either were exclusively present in these samples or oc- curred at significantly higher rates compared with the control samples. Amounts of 6-methyl-5-hepten-2-one, indole, and 5 fatty acids (acetic, propionic, butanoic, 3-methylbutanoic, and pentanoic acids) were significantly higher in the estrous samples collected at the peak of pheromone release compared with those collected $6 \mathrm{~d}$ before ovulation (Figure 1; Table 1).

Quantification data of putative sex pheromone components revealed that during the peak release period, $36 \pm 8 \mathrm{ng}$ (average $\pm \mathrm{SE}$ ) of acetic acid and $10 \pm 3$ ng of propionic acid were present in $0.5 \mathrm{~g}$ of estrous fecal samples compared with $19 \pm 5$ and $2.3 \pm 1 \mathrm{ng}$ of acetic and propionic acids, respectively, in the control diestrous samples. The third putative sex pheromone component, 1-iodoundecane, was not detected by SPME or solvent extraction with diethyl ether. The detection limit of synthetic 1-iodoundecane was 500 $\mathrm{pg} / 0.5 \mathrm{~g}$ of feces by SPME when GC/MS was operated in SIM mode.

\section{Temporal Patterns of Compounds in the Headspace of Fecal Samples Before, During, and After the Ovulation Period}

Acetic and propionic acids are 2 bovine putative sex pheromone components that were detected in all 
samples analyzed, including the control samples taken $6 \mathrm{~d}$ before and $7 \mathrm{~d}$ after ovulation. Quantitative low levels of the acids were observed until $1 \mathrm{~d}$ before ovulation (Figure 2), at which point their concentrations increased, reaching a peak around $0.5 \mathrm{~d}$ before ovulation (Figure 2). After this peak, the amounts of the compounds decreased sharply back to the levels of the control samples and remained low until sampling was completed. This decrease in the amounts of putative sex pheromone components coincides temporally with the end of the theoretical period of estrus.

The amounts of 6-methyl-5-hepten-2-one and indole peaked at various intervals with respect to ovulation (Figure 3). The peaks of butanoic, 3-methylbutanoic, and pentanoic fatty acids were generally registered from 6 to $13 \mathrm{~h}$ before ovulation, although peaks of butanoic and pentanoic acids occurred 1 and $6 \mathrm{~d}$ before ovulation in the samples from cows 2,122 and 8,256, respectively (Figure 3).

\section{DISCUSSION}

Like other mammalian species, cows have been proposed to use sex pheromones to signal their reproductive status, evoke sexual behavior, and increase sperm quantity of bulls (Vytas et al., 2012; Archunan et al., 2014; Le Danvic et al., 2015; Nordéus et al., 2016). Results from studies on bovine pheromones vary greatly. There are several possible explanations for this variation, ranging from differences in methods of sample collection, analysis, and bioassay to peculiarities of the sex communication system (Nordéus et al., 2016). Acetic and propionic acids as well as 1-iodoundecane have been identified as putative sex pheromone components in cow feces and were shown to be unique in the estrous phase (Sankar and Archunan, 2008). Contrary to these findings, however, our study identified only 2 of these 3 putative sex pheromone components (i.e., acetic and propionic acids) in fecal samples, whereas 1-iodoundecane was not detected by SPME or solvent extraction with diethyl ether. Following the extraction procedure described by Sankar and Archunan (2008) and using synthetic 1-iodoundecane, we were able to reach the detection limits of 1-iodoundecane as low as $500 \mathrm{pg} / 0.5$ $\mathrm{g}$ of feces. Unfortunately, no quantification data of putative sex pheromone components were published in their study, which would have allowed for a comparison of the detection limits. In our experiments, 2 injections of the hormone $\mathrm{PGF}_{2 \alpha}$ were administered over a 2 -wk interval to induce and synchronize the estrous cycles in the group of the cows. This may have been insufficient to induce the production of 1-iodoundecane at detectable amounts compared with the results from Sankar and Archunan (2008), where natural-cycling cows were studied. Our samples were collected from Holstein cows, whereas Jersey cows were used in the study conducted by Sankar and Archunan (2008). However, variations in the composition of sex pheromones among breeds is unlikely because no data indicate interbreed mating restrictions.

By using a more sensitive analytical method that enables the detection of lower concentrations of shortchain fatty acids compared with Sankar and Archunan (2008), we found that both acids were present in estrous and diestrous fecal samples and reached their maximum values at $0.5 \mathrm{~d}$ before ovulation. Our data did not support previous findings that suggested that the chemical profiles of feces of estrous-phase cows were distinguished from feces collected during the diestrous phase by the exclusive presence of acetic and propionic acids (Sankar and Archunan, 2008). The samples from the first control group were collected $11 \mathrm{~d}$ after the first injection of hormones. Some of the acetic and propionic acids present in pre-estrous samples could be a consequence of this treatment. However, samples from the second control group were obtained 1 wk after ovulation, and consequently the presence of these 2 acids was an unexpected finding in the postestrous fecal samples.

In our experiments, the cows did not receive forage containing acetic and propionic acids, although these additives are commonly used in silages to inhibit spoilage (Danner et al., 2003; Salcedo et al., 2010). As such, the increased rates of these acids as a possible effect of their increased external uptake in diestrous cows is ruled out.

Four substances, including butanoic and pentanoic acids, were reported as pre-estrous specific compounds by Sankar and Archunan (2008). We detected those 2 acids in all samples, and their peaks were generally registered around the middle of estrus (with the exception of 1 and $6 \mathrm{~d}$ before ovulation in the samples from cows 2,122 and 8,256, respectively). Amounts of these 2 acids decreased sharply 4 to $11 \mathrm{~h}$ before ovulation and remained low until sampling was completed. Similar to our findings, the presence of 6 VFA (including acetic, propionic, butanoic, and pentanoic acids) in diestrous fecal samples of naturally cycling cows was reported by Hradecký (1986). Most likely, butanoic and pentanoic acids were not detected in postestrous samples by Sankar and Archunan (2008) because of the less sensitive quantification method they used. For the same reason, the amounts of 2 acids could be undetected by their method if estrous samples were collected in the late period of estrus.

Mating within a short period $(12-22 \mathrm{~h})$ on the day of estrus is a prerequisite for optimal fertilization rates in cows (Schams et al., 1977). Our data showed that the amounts of acetic and propionic acids began to 
increase $1 \mathrm{~d}$ before ovulation and peaked around 0.5 $\mathrm{d}$ before ovulation, correlating with the optimal time of insemination. We observed high variability in the quantity of these 2 acids among cows. It is possible that the large variability of acetic and propionic acid levels among animals could be explained by the hormonal induction of estrus. However, the amounts of butanoic, 3 -methylbutanoic, and pentanoic acids, which have no
Cow 1061

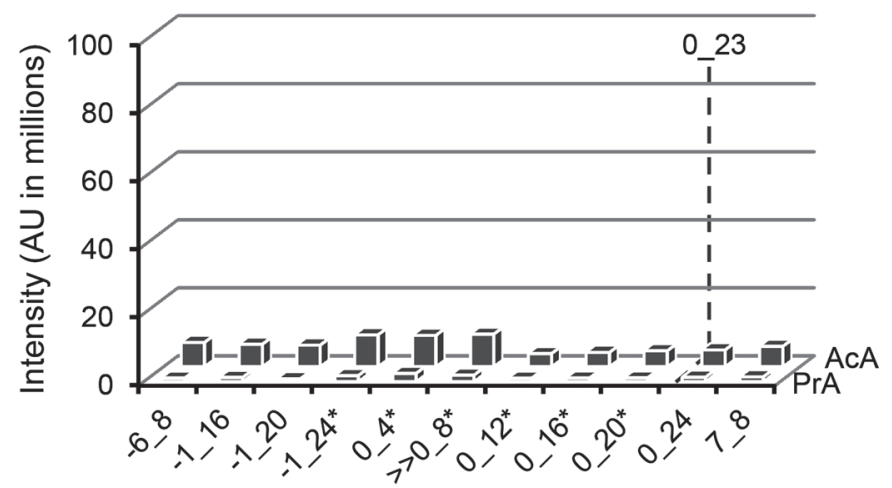

Cow 2122

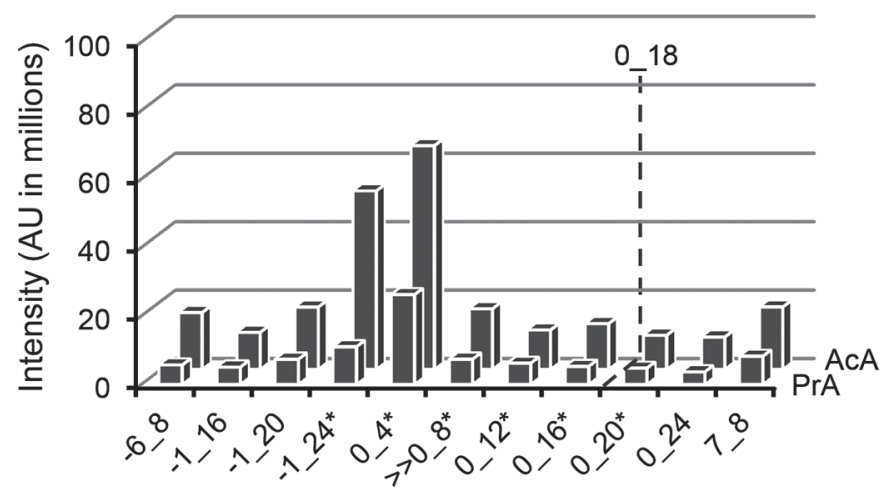

Cow 8175

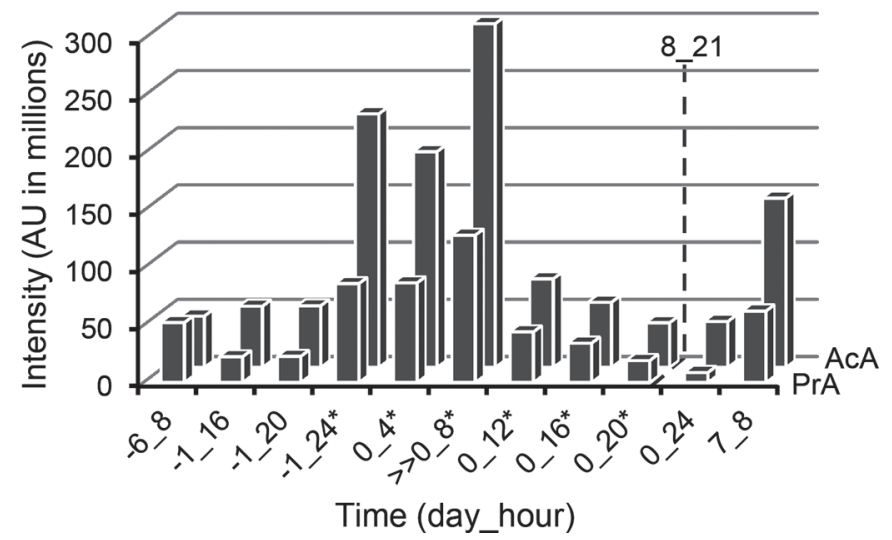

Cow 1076

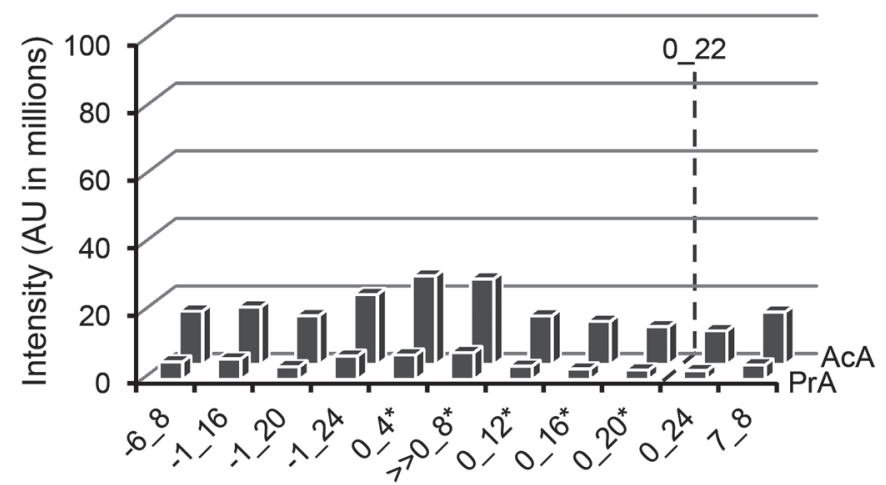

Cow 6682

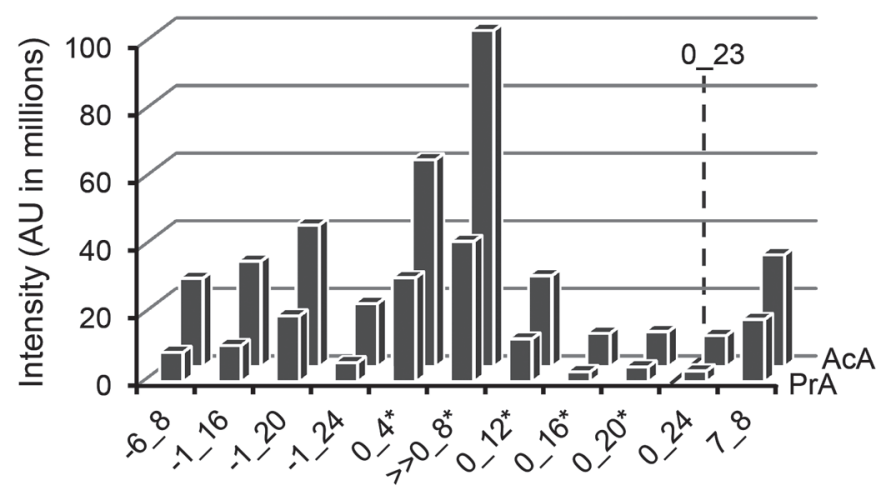

Cow 8256

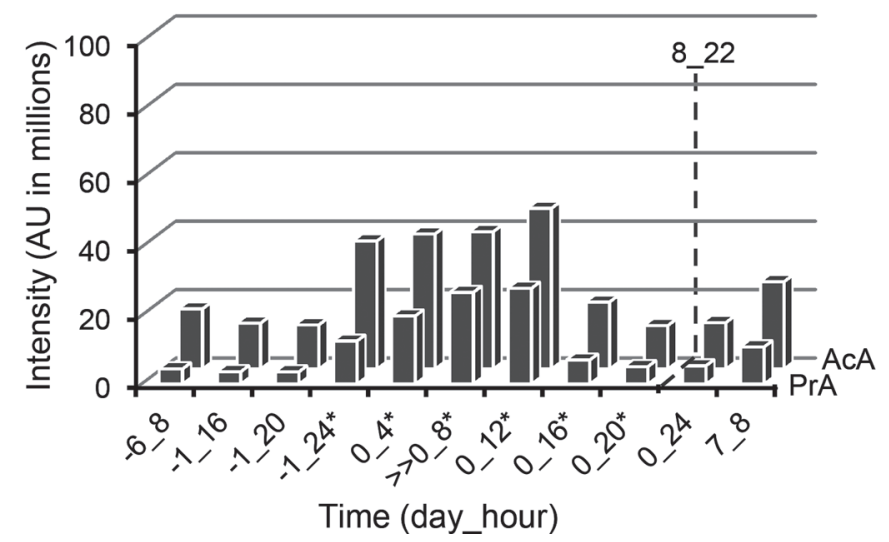

Figure 2. Temporal patterning of 2 putative sex pheromone components in the headspace of fecal samples during hormone-induced estrus in cows. The text above each graph indicates the cow identification number. Intensity values presented on the $y$-axis indicate the abundance of the

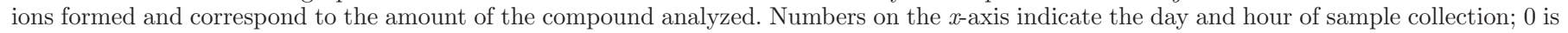
the day of ovulation. Samples labeled $-6 \_8$ and $7 \_8$ are control samples collected 6 d before and $7 \mathrm{~d}$ after ovulation, respectively; $>>$ indicates

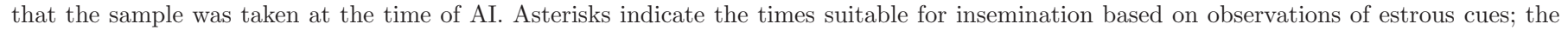
dashed line indicates the time of ovulation. $\operatorname{PrA}=$ propanoic acid; AcA = acetic acid. 
Cow 1061

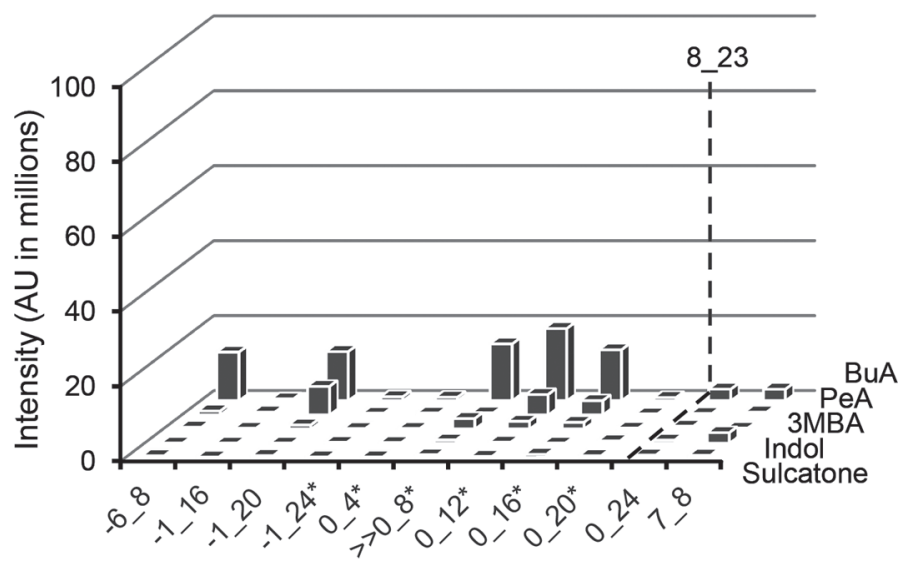

Cow 2122

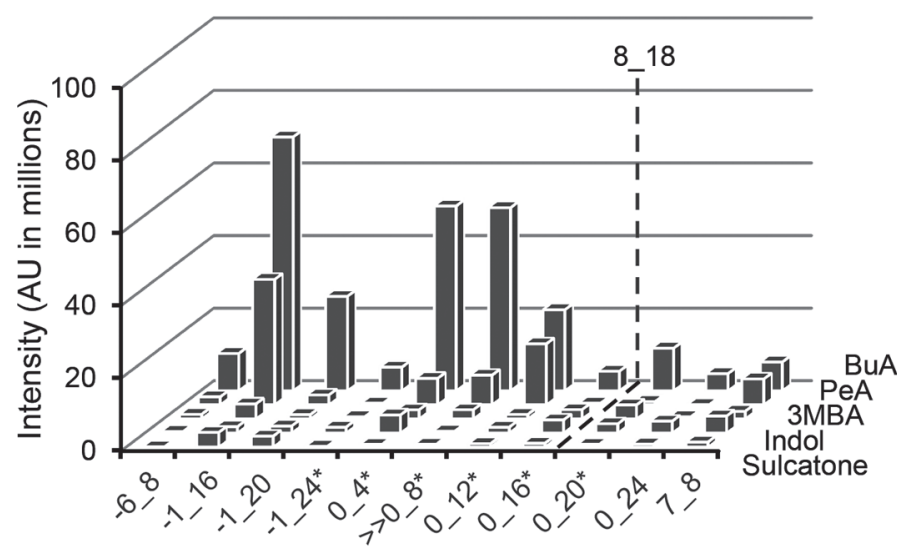

Cow 8175

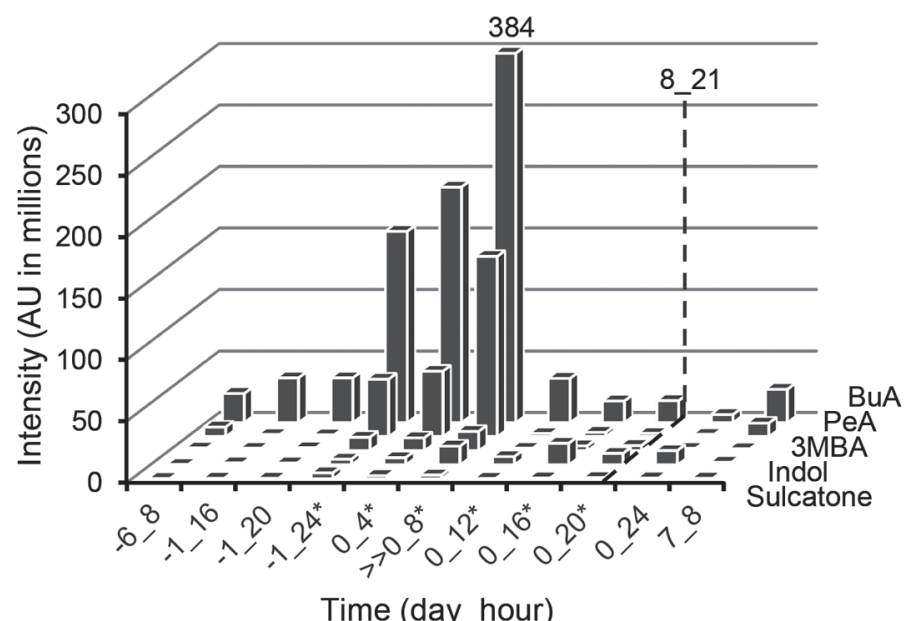

Time (day_hour)
Cow 1076

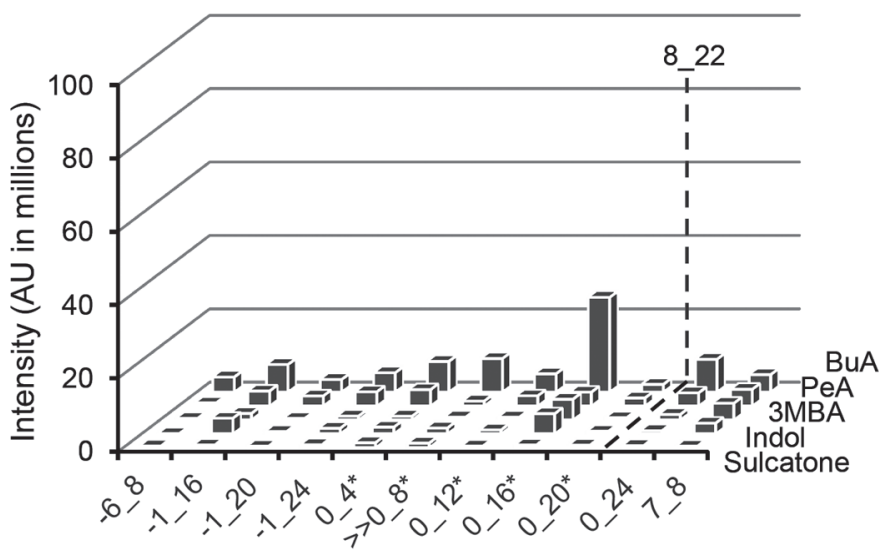

Cow 6682

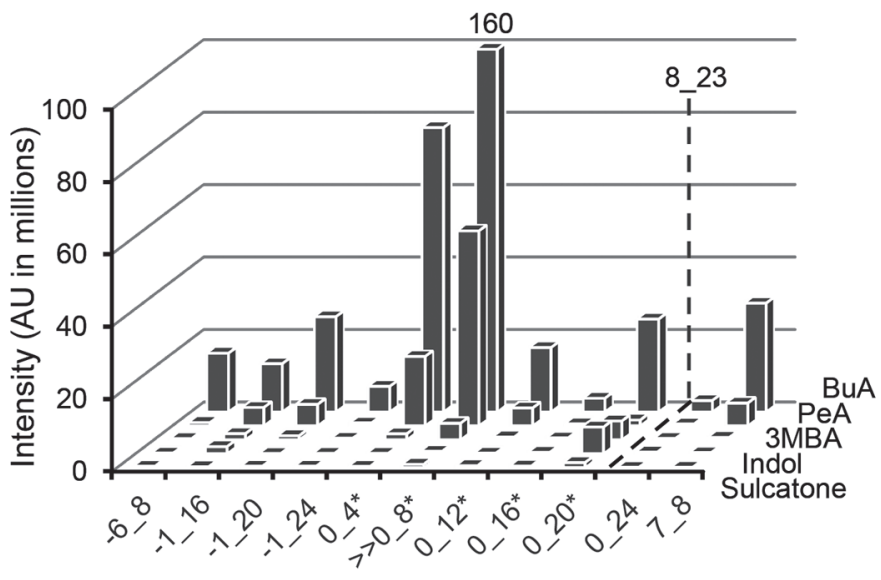

Cow 8256

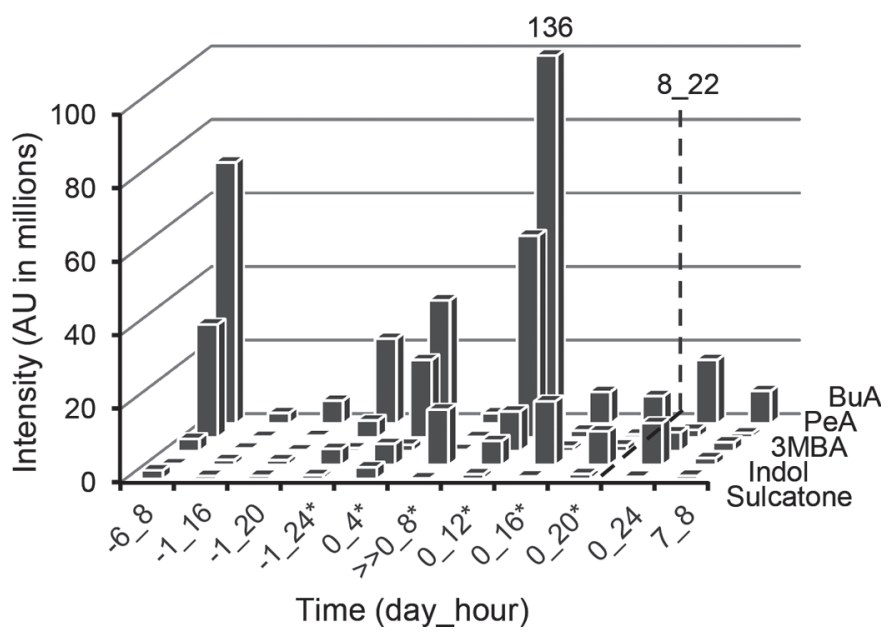

Figure 3. Temporal patterning of 5 selected compounds in the headspace of fecal samples during hormone-induced estrus in cows. Pheromone activity of the selected compounds is unknown, and their amounts differ significantly in estrous and control samples (Table 1). The text above each graph indicates the cow identification number. Intensity values presented on the $y$-axis indicate the abundance of the ions formed and correspond to the amount of the compound analyzed. The numbers above some columns representing butyric acid indicate intensity values of the compound that scale past the maximum value on the $y$-axis. Numbers on the $x$-axis indicate the day and hour of sample collection; 0 is the day of ovulation. Samples labeled $-6 \_8$ and $7 \_8$ are control samples collected $6 \mathrm{~d}$ before and $7 \mathrm{~d}$ after ovulation, respectively; $>>$ indicates that the sample was taken at the time of AI. Asterisks indicate the times suitable for insemination based on observations of estrous cues; the dashed line indicates the time of ovulation. $3 \mathrm{MBA}=3$-methylbutanoic acid; $\mathrm{PeA}=$ pentanoic acid; $\mathrm{BuA}=$ butanoic acid. 
reported pheromone activity, were larger in the same cows as well. Moreover, our preliminary data showed large quantitative variations of acetic and propionic acid levels in the fecal samples from naturally cycling cows (R. Mozūraitis, unpublished data), indicating that the hormone treatment was not a major cause of large variations in the acid levels among cows. Over the last few decades, focus on increasing milk production resulted in a decline of reproductive performance in dairy cows affecting various reproductive functions (LeBlanc, 2010; Walsh at al., 2011) and possibly increased individual variation of sex pheromone production. In our experiments, the registration of behavioral estrus cues was carried out using qualitative measures (i.e., presence vs. absence) rather than quantitative measures. As such, there is not enough resolving power to determine the correlation between acetic and propionic acid level variability and behavioral estrus cues.

Several other body excretions and fluids, in addition to feces, contain estrus-specific chemical cues in cows. For example, it was reported that behavioral reactions of bulls differ in response to estrous versus diestrous samples of urine, vaginal fluids, saliva, and serum ( $\mathrm{Vy}$ tas et al., 2012; Archunan et al., 2014; Le Danvic et al., 2015).

To our knowledge, acetic and propionic acids, 2 putative sex pheromone components, were reported as estrus-specific compounds in vaginal fluids (Sankar and Archunan, 2011) and saliva (Sankar at al., 2007), whereas 1-iodoundecane was the only putative sex pheromone component identified in estrous cow urine (Kumar et al., 2000). However, the data presented by Hradecký (1986) indicated the presence of both acetic and propionic acids in vaginal secretions and urine samples during both the diestrous and estrous phases of naturally cycling cows. In addition, our early data show that both estrous and diestrous urinary samples contain acetic and propionic acids, whereas 1-iodoundecane was not detected in these samples (R. Mozūraitis, unpublished data). Recently, Le Danvic et al. (2015) reported 6 compounds that were present in urine with levels that specifically increased at the pre-estrous and estrous stages. These authors found that synthetic molecules of 2-butanone and oleic acid significantly lowered mounting reaction time and ejaculation time, whereas the binary mixture of squalene and 1,2-dichloroethylene induced increased sperm quantity of bulls. These compounds were not identified in the fecal samples taken in this study with the exception of coumarin, which was detected in a few samples at trace levels, and oleic acid (i.e., octadecanoic acid), for which amounts did not differ significantly between estrous and control samples. Squalene might not be volatile enough to be detected by the SPME technique we used.
The use of an electronic nose for the routine determination of optimal insemination time in cows requires the reliable excretion of volatile chemical markers, where the absolute concentrations show clear, reproducible, temporal patterning and provide information about the timing of ovulation. Moreover, the matrix containing these markers has to be easy to collect and quantify. The occurrence of acetic and propionic acids in all fecal samples, regardless of the stage in the cycle, and high variability in the quantity of these 2 acids among cows make the detection of estrus more problematic because of the need to monitor concentration changes rather than recording only the presence or absence of the compounds. It should be noted that in addition to acetic and propionic acids, butanoic, 3-methylbutanoic, and pentanoic fatty acids were present in the samples, and their absolute levels showed less defined temporal patterning. As such, these compounds should also be taken into consideration when designing sensors for artificial olfaction systems. Our preliminary data obtained by a prototype of an electronic nose showed that correlations between GC/MS measurements for acetic and propionic acids and electronic nose measurements are in the range of 0.8 to 0.88 for the samples of 6 cows (R. Mozūraitis; unpublished data).

In conclusion, acetic and propionic acids were detected in fecal samples of cows. Despite large variations among animals, the absolute levels of these acids showed temporal patterning, were reproducible, and provided information about the timing of ovulation. Further research is needed to examine quantitative differences in the levels of acetic and propionic acids in fecal samples of cows with clear and weak or visually undetectable standing estrus.

\section{ACKNOWLEDGMENTS}

This study was supported by EU Seventh Framework Programme Capacities grant no. 232460 titled "Pheromone-based sensor systems for detecting estrus in dairy cows." We thank Vilius Viskontas, director of Lytagros Agricultural Company, for his kind support of the research performed at the Bernatonys dairy farm, Kaunas district, Lithuania. We are grateful to Allison Perrigo for improving the language of the manuscript.

\section{REFERENCES}

Agilent Technologies Inc. 2012. Agilent J\&W GC column selection guide. Accessed Nov. 19, 2016. www.agilent.com/cs/library/ catalogs/public/5990-9867EN_GC_CSG.pdf.

Archunan, G., S. Rajanarayanan, and K. Karthikeyan. 2014. Cattle pheromones. Pages 461-487 in Neurobiology of Chemical Communication. C. Mucignat-Caretta, ed. CRC Press, London, United Kingdom. 
Bloch, A., Y. Folman, M. Kaim, Z. Roth, R. Braw-Tal, and D. Wolfenson. 2006. Endocrine alterations associated with extended time interval between estrus and ovulation in high-yield dairy cows. J. Dairy Sci. 89:4694-4702.

Burlachenko, J., I. Kruglenko, B. Snopok, and K. Persaud. 2016. Sample handling for electronic nose technology: State of the art and future trends. Trends Analyt. Chem. 82:222-236.

Dalton, J. C., S. Nadir, J. H. Bame, M. Noftsinger, R. L. Nebel, and R. G. Saacke. 2001. Effect of time of insemination on number of accessory sperm, fertilization rate, and embryo quality in nonlactating dairy cattle. J. Dairy Sci. 84:2413-2418.

Danner, H., M. Holzer, E. Mayrhuber, and R. Braun. 2003. Acetic acid increases stability of silage under aerobic conditions. Appl. Environ. Microbiol. 69:562-567.

Hernández-Cerón, J., L. Zarco, and V. Limatamayo. 1993. Incidence of delayed ovulation in Holstein heifers and its effects on fertility and early luteal function. Theriogenology 40:1073-1081.

Hockey, C. D., J. M. Morton, S. T. Norman, and M. R. McGowan. 2010. Improved prediction of ovulation time may increase pregnancy rates to artificial insemination in lactating dairy cattle. Reprod. Domest. Anim. 45:e239-e248.

Hradecký, P. 1986. Volatile fatty acids in urine and vaginal secretions of cows during reproductive cycle. J. Chem. Ecol. 12:187-196.

Kolb, B., and L. S. Ettre. 2006. Static Headspace-Gas Chromatography: Theory and Practice. 2nd ed. Wiley, Hoboken, NJ.

Kumar, K. R., G. Archunan, R. Jeyraman, and S. Narasimhan. 2000. Chemical characterization of bovine urine with special reference to estrous cycle. Vet. Res. Commun. 24:445-454.

Le Danvic, C., O. Gérard, E. Sellem, C. Ponsart, P. Chemineau, P. Humblot, and P. Nagnan-Le Meillour. 2015. Enhancing bull sexual behavior using estrus-specific molecules identified in cow urine. Theriogenology 83:1381-1388.

LeBlanc, S. 2010. Assessing the association of the level of milk production with reproductive performance in dairy cattle. J. Reprod. Dev. 56:S1-S7.

Lima, F. S., A. de Vries, C. A. Risco, J. E. P. Santos, and W. W. Thatcher. 2010. Economic comparison of natural service and timed artificial insemination breeding programs in dairy cattle. J. Dairy Sci. 93:4404-4413.

Mills, G. A., and V. Walker. 2000. Headspace solid-phase microextraction procedures for gas chromatographic analysis of biological fluids and materials. J. Chromatogr. A 902:267-287.

Nordéus, K., R. Båge, H. Gustafsson, R. Glinwood, and L. Söderquist. 2016. A small expose on bovine pheromones: With special reference to modifications of the reproductive cycle. Pages 33-42 in Chemical Signals in Vertebrates. Vol. 13. B. A. Schulte, T. A. Goodwin, and M. H. Ferkin, ed. Springer International, Cham, Switzerland.

Pursley, J. R., R. W. Silcox, and M. C. Wiltbank. 1998. Effect of time of artificial insemination on pregnancy rates, calving rates, pregnancy loss and gender ratio after synchronization of ovulation in lactating dairy cows. J. Dairy Sci. 81:2139-2144.
Roelofs, J., F. López-Gatius, R. H. F. Hunter, F. J. C. M. van Eerdenburg, and C. Hanzen. 2010. When is a cow in estrus? Clinical and practical aspects. Theriogenology 74:327-344.

Roelofs, J. B., E. A. M. Graat, E. Mullaart, N. M. Soede, W. Voskamp-Harkema, and B. Kemp. 2006. Effects of insemination-ovulation interval on fertilization rates and embryo characteristics in dairy cattle. Theriogenology 66:2173-2181.

Saacke, R. G. 2008. Insemination factors related to timed AI in cattle. Theriogenology 70:479-484.

Salcedo, G., L. Martinez-Suller, H. Arriaga, and P. Merino. 2010. Effects of forage supplements on milk production and chemical properties, in vivo digestibility, rumen fermentation and $\mathrm{N}$ excretion in dairy cows offered red clover silage and corn silage or dry ground corn. Ir. J. Agric. Food Res. 49:115-128.

Sankar, R., and G. Archunan. 2008. Identification of putative pheromones in bovine (Bos taurus) faeces in relation to estrus detection. Anim. Reprod. Sci. 103:149-153.

Sankar, R., and G. Archunan. 2011. Gas chromatographic/mass spectrometric analysis of volatile metabolites in bovine vaginal fluid and assessment of their bioactivity. Int. J. Anal. Chem. 2011:256106.

Sankar, R., G. Archunan, and Y. Habara. 2007. Detection of oestrousrelated odour in bovine (Bos taurus) saliva: Bioassay of identified compounds. Animal 1:1321-1327.

Sankaran, S., L. R. Khot, and S. Panigrahi. 2012. Biology and applications of olfactory sensing system: A review. Sens. Actuator. B Chemical 171-172:1- 17 .

Saumande, J. 2002. Electronic detection of oestrus in postpartum dairy cows: Efficiency and accuracy of the DEC (R) (showheat) system. Livest. Prod. Sci. 77:265-271.

Saumande, J., and P. Humblot. 2005. The variability in the interval between estrus and ovulation in cattle and its determinants. Anim. Reprod. Sci. 85:171-182.

Schams, D., E. Schallenberger, B. Hoffmann, and H. Karg. 1977. The oestrous cycle of the cow: Hormonal parameters and time relationships concerning oestrus, ovulation, and electrical resistance of the vaginal mucus. Acta Endocrinol. (Copenh.) 86:180-192.

Sokal, R. R., and F. J. Rohlf. 1995. Biometry. Freeman, New York, NY.

Stevenson, J. S., S. L. Hill, R. L. Nebel, and J. M. Dejarnette. 2014 Ovulation timing and conception risk after automated activity monitoring in lactating dairy cows. J. Dairy Sci. 97:4296-4308.

Van Eerdenburg, F. J., D. Karthaus, M. A. M. Taverne, I. Merics, and O. Szenci. 2002. The relationship between estrous behavioral score and time of ovulation in dairy cattle. J. Dairy Sci. 85:1150-1156.

Vytas, S., C. Briant, P. Chemineau, C. Le Danvic, and P. Nagnan-Le Meillour. 2012. Oestrus pheromones in farm mammals, with special reference to cow. Indian J. Anim. Sci. 82:256-267.

Walsh, S. W., E. J. Williams, and A. C. O. Evans. 2011. A review of the causes of poor fertility in high milk producing dairy cows. Anim. Reprod. Sci. 123:127-138. 